\title{
Experimental dental caries in the albino rat
}

\author{
Incidence of caries in animals maintained on powdered purified diets \\ containing either $67 \%$ sucrose or $67 \%$ potato starch
}

\author{
By R. L. HARTLES AND F. E. LAWTON \\ School of Dental Surgery, University of Liverpool \\ (Received 16 May 1956-Revised 27 September 1956)
}

Several workers have shown that certain strains of albino rat and cotton rat develop dental caries when they are maintained on powdered purified diets containing $67 \%$ sucrose (McClure, 1945; Sognnaes, 1948; Shaw, 1950; Hartles, Lawton \& Slack, 1956; Schweigert, Shaw, Phillips \& Elvehjem, 1945). In the cotton rat the substitution of finely divided starch or dextrin for all or part of the sucrose has been shown to reduce the incidence of caries (Schweigert et al. 1945; Schweigert, Potts, Shaw, Zepplin \& Phillips, 1946).

In the present study wehave observed the effect of replacing the whole of the sucrose in the diet with potato starch. In these circumstances there was a marked decrease in the incidence of dental caries in the group receiving starch when compared with the incidence in animals on the high-sucrose diet. The rate of growth of the animals was considerably retarded on the potato-starch diet. This particular starch has been used extensively in producing refection in rats (Kon, Kon \& Mattick, I938; Kon, 1945). We happened to have a quantity of potatos starch available and since no report could be found of its use in an experimental investigation of caries it was of interest to study the effect of this starch on the incidence of dental caries.

\section{EXPERIMENTAL}

Animals. Twelve litters of rats bred from our own caries-susceptible colony were weaned at 4 weeks and distributed into two groups of forty each containing equal numbers of males and females. The animals were housed and maintained as described earlier (Hartles et al. 1956).

Diets. Group I animals continued to receive diet $\mathrm{HS}$ r containing $67 \%$ sucrose (Hartles et al. 1956); this is the normal diet of the colony. At weaning, group 2 animals received diet $\mathrm{HS}_{2}$ which contained $67 \%$ potato starch (Superfine Farina Starch, Corn Products Co. Ltd) in place of sucrose. The starch was in the form of a very fine powder, none of which was retained on a roo-mesh sieve. In other respects the two diets were identical except for their water content. To achieve the same consistency of the diet, so that it would just hold together when squeezed firmly in the hand, it was necessary to add twice as much water $(c .200 \mathrm{ml}$.) to each $\mathrm{kg}$ of the starch diet as to the sucrose diet. It was considered desirable to achieve the same consistency as far as possible so that any scattering of the diets should be similar.

When 26 weeks old the rats were killed with ether and the teeth examined and scored as previously described (Hartles et al. 1956). 
General condition of animals. The general health of the rats on the sucrose diet (group I) continued to be good. Two animals, one male and one female, died after 5 weeks on the potato-starch diet. Post-mortem examination of these rats revealed grossly distended stomachs whilst the lower gut was almost empty. The animals of group 2 were less active and showed poorer muscle tone than those of group 1.

Growth of animals. The rats of group 2 grew much less rapidly than those in group $\mathrm{I}$. Growth curves constructed from the mean weights of each group are shown in Fig. $x$. The differences in growth between males in groups $\mathrm{I}$ and 2 , and between females in groups I and 2, were statistically highly significant. The probability of their being due to chance was in both less than $\mathrm{I}:$ rooo. The mean gains per week (in g) with their standard errors were as follows:

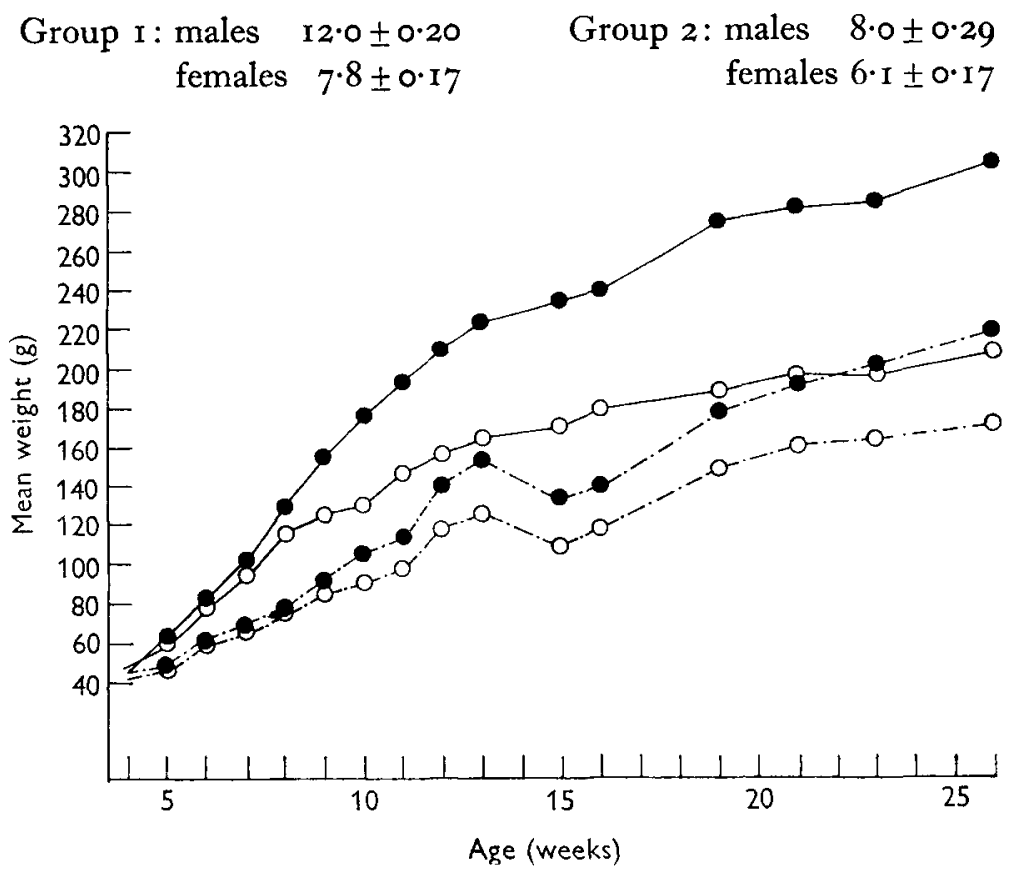

Fig. I. Mean growth curves of forty rats on the diet containing $67 \%$ sucrose (group I) and of thirtyeight rats on the diet containing $67 \%$ potato starch (group 2). $-\bullet$, group I, males; $\bigcirc-0$, group I, females; $\bullet-\cdot-\cdot \bullet$, group 2 , males; $0-\cdot-\cdot-\circ$, group 2 , females.

Condition of teeth. In group I, thirty of the forty animals had carious teeth; the mean number of carious teeth per rat was $\mathrm{r} \cdot 8$. There was very little attrition of the occlusal surfaces of the molars. In group 2, eleven of the thirty-eight animals had carious teeth, the mean number of carious teeth per rat being 0.5 . No tooth in this group was given a score greater than I, denoting the earliest detectable stage of caries. The rats receiving the starch diet had rather more attrition of the molar teeth than those receiving the sugar diet, as a result of which the depth of the fissures was reduced. The detailed results are given in Table $\mathrm{I}$. 


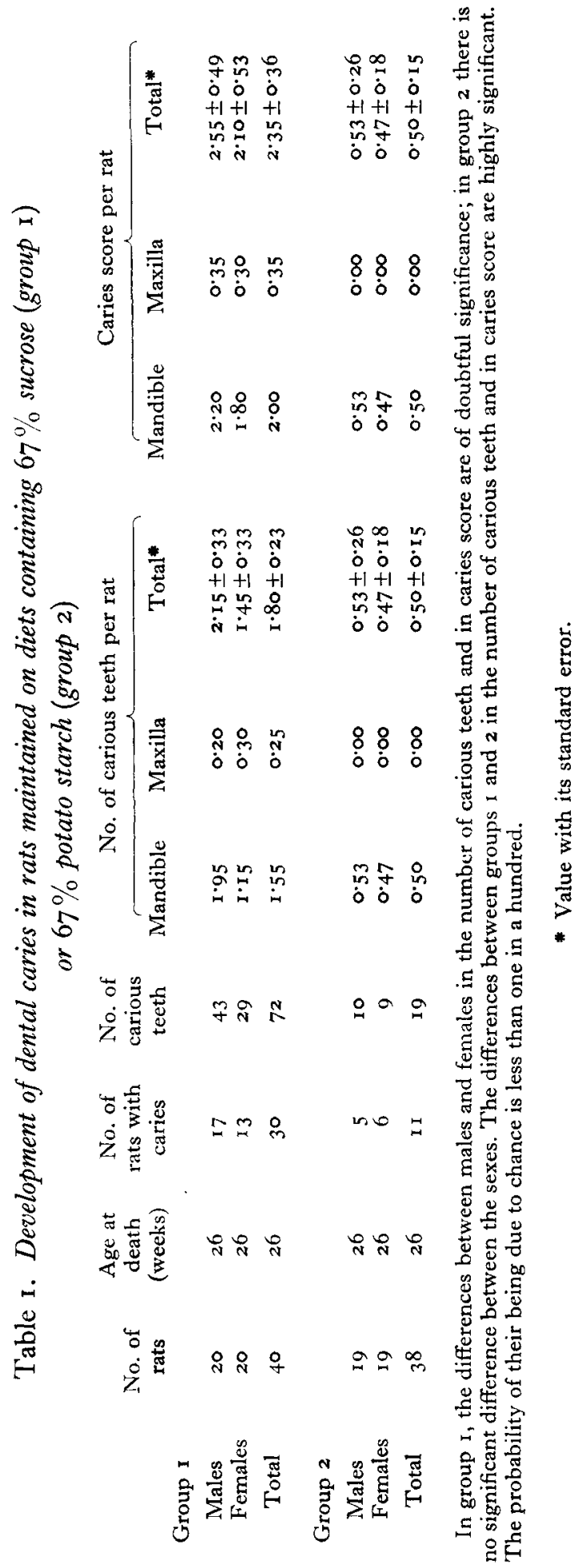




\section{DISCUSSION}

The replacement of sucrose in the diet of the rats by potato starch produced two observable facts. First, the rate of growth was significantly less on the starch diet than on the sucrose diet. Secondly, the mean number of carious teeth per animal was reduced from $\mathrm{x} \cdot 8$ to 0.5 , the corresponding caries scores being 2.35 and 0.5 .

Shaw (1950) showed that, in weanling caries-susceptible albino rats, the isocaloric substitution of fat and protein for part of the sucrose in the purified ration resulted in a substantial reduction in the incidence of dental caries. However, there do not appear to be any reports of the effect of total replacement of sucrose by starch on the incidence of tooth decay in the albino rat. Schweigert et al. (I945) placed cotton rats on a purified diet containing $67 \%$ soluble starch, the nature of which is not specified; the animals died after 3 weeks on this diet. Similar results were obtained with finely ground dextrin. When coarse dextrin (unspecified particle size) was used the animals survived, grew well and had a low incidence of dental caries. These authors suggested that the unsatisfactory growth of the animals maintained on diets containing starch and fine dextrin was largely due to scattering of the food by the animals, as a consequence of which the consumption of food was low. However, in a later report (Schweigert et al. 1946) they were able to maintain six animals on a $67 \%$ starch diet for I4 weeks. A low incidence of caries was observed in these animals but their growth rate was little more than half that of controls receiving the sucrose diet.

In our animals scattering of the diet was not an important factor for it was moistened sufficiently to minimize this hazard. The increased water content of the starch diet was not considered to result in a lowered food intake since in general the animals receiving the diet ate more than did their fellows on the sucrose diet. A considerable quantity of starch was excreted in the faeces which were bulky and pale in colour. This pattern was similar to that observed by many workers in refected rats. In contrast, the faeces of animals receiving the sucrose diet were small and black. It would seem, therefore, that the impaired growth is attributable, at least in part, to poor utilization of the potato starch.

Potato starch has been used in the production of refected rats. Refection was first described by Fridericia (1926) as 'a transmissible change in the intestinal content enabling rats to grow and thrive without B-vitamin in the food'. In the condition of refection certain starches, notably raw potato starch, allow rats to grow in the absence of dietary B-vitamins. It is now believed that the potato starch which is incompletely digested, and is therefore found in the lower gut, alters the intestinal environment so that the flora is able to produce a sufficient quantity of the B-vitamins for the animal to thrive (Kon, 1945; Ford, Henry, Kon, Porter, Thompson \& Wilby, 1953). Our animals received adequate dietary supplements of vitamins and limitations on their growth were likely to be due to the poor utilization of the potato starch. Kon et al. (1938) believed that refected rats grew normally with or without dietary B-vitamins. Their diet, however, included $17 \%$ sucrose, whereas in our diet potato starch was the only carbohydrate. Bliss (1936) obtained good growth in a rat which had received a diet containing raw potato starch but which was deficient in B-vitamins. However, it 
grew less well than a rat receiving a diet containing cane sugar in place of potato starch and to which yeast had been added. He suggested that this difference in growth was due to an initial lag phase during which refection becomes established. Our results do not support this view. The growth of both male and female rats in group I (sucrose diet) was significantly greater than that of group 2 animals (potato-starch diet).

We conclude that a diet containing adequate vitamins, minerals, protein and fat, but in which the sole carbohydrate was potato starch, gave less satisfactory growth in the rat than a similar diet in which the carbohydrate was sucrose.

There was a marked difference in the incidence and extent of caries between the two groups. These differences are statistically highly significant (see Table I). In group $\mathrm{r}$, thirty of forty animals had dental caries and eleven of them had teeth scored 2 or 3 . In group 2 , only eleven of thirty-eight rats developed dental caries and in no instance was a tooth given a score greater than $\mathrm{r}$. There is therefore no doubt that, in our rats, the potato-starch diet is less conducive to the development of caries than is the sucrose diet. It is possible that, on the starch diet, the slight increase in attrition of the molar teeth, which renders the fissures less deep, may militate against the development of caries. In our opinion, however, this is unlikely to be a major factor in the lessened incidence of the disease in the rats of group 2.

\section{Incidence of caries on the sucrose diet}

Examination of Table $I$ shows that in group $I$ the males appeared to have had a greater number of carious teeth per animal and a larger caries score than the females. This difference is, however, of doubtful significance, the probability of its being due to chance lying between $\mathrm{r}: 5$ and $\mathrm{I}: \mathrm{r}$.

Both the incidence of caries and its severity were much less in our animals than has been reported by other workers. The colony has been bred from a few animals obtained from the caries-susceptible strain maintained at the Harvard School of Dental Medicine. Shaw (1950), using rats of this parent colony which received a similar high-sucrose diet, found the average number of carious teeth per animal to be between 4.5 and 8.8 at 14 weeks old. This is a very much higher value than our own of $\mathrm{I} \cdot 8$ at 26 weeks. In a previous study (Hartles et al. 1956 ) we observed $2 \cdot 2$ carious teeth per rat after 26 weeks. We have not yet determined the reason for this decreased susceptibility, but attempts are being made to increase the incidence and severity of dental caries in our colony. Our animals are the direct descendants of some of the Harvard animals, they receive similar diets containing $67 \%$ sucrose, and yet have much less caries. It would appear therefore, that a high sucrose content of the diet is not the only factor in the production of caries in this strain of rat.

\section{SUMMARY}

I. Eighty rats bred on a diet containing $67 \%$ sucrose were divided at weaning into two equal groups. Group I continued to receive the sucrose diet; group 2 received a diet in which all the sucrose was replaced by potato starch. Two rats in group 2 died after 5 weeks, and values for them are not included in the results. 
2. Animals of group 2 grew at a significantly slower rate and were less active than those of group I.

3. At 26 weeks old group I animals had an average of $\mathrm{I} \cdot 8$ carious teeth per rat; in group 2 the corresponding figure was 0.5 . This difference is highly significant.

4. Even on the sucrose diet the incidence and severity of the observed dental caries was less than that reported by other workers.

The authors wish to thank Mr R. P. Williams for his care and maintenance of the animals.

Grateful thanks are due to Messrs J. Bibby and Sons Ltd for the gift of groundnut oil; to Evans Medical Supplies Ltd for the gift of 'Hepamino'; to Messrs Tate and Lyle Ltd for the gift of icing sugar.

Bliss, S. (1936). F. Nutr. II, I.

REFERENCES

Ford, J. E., Henry, K. M. Kon, S. K., Porter, J. W. G., Thompson, S. Y. \& Wilby, F. W. (1953). Brit. F. Nutr. 7, 67 .

Fridericia, L. S. (1926). Skand. Arch. Physiol. 49, 55.

Hartles, R. L., Lawton, F. E. \& Slack, G. L. (1956). Brit. F. Nutr. 10, 234.

Kon, P. M., Kon, S. K. \& Mattick, A. T. R. (1938). F. Hyg., Camb., 38, r.

Kon, S. K. (1945). Proc. Nutr. Soc. 3, 217.

McClure, F. J. (1945). F. dent. Res. 24, 239.

Schweigert, B. S., Shaw, J. H., Phillips, P. H. \& Elvehjem, C. A. (1945). F. Nutr. 29, 405.

Schweigert, B. S., Potts, E., Shaw, J. H. Zepplin, M. \& Phillips, P. H. (1946). F. Nutr. 32, 405.

Shaw, J. H. (1950). F. Nutr. 4r, 13.

Sognnaes, R. F. (1948). F. Amer. dent. Ass. 37, 676.

\title{
On the role of corticoids in conditioning the gastric mucosa to certain toxic actions of ergocalciferol
}

\author{
BY H. SELYE AND P. BOIS \\ Institut de Médecine et de Chirurgie expérimentales, Université de Montréal, \\ Montreal, Canada
}

(Received 18 June 1956)

It was evident from the first systematic studies on the pathological histology of ergocalciferol intoxication that the stomach is particularly often and severely affected by overdosage with this vitamin. Rats treated with heavy doses of Vigantol (an irradiated ergosterol preparation kindly supplied by Merck and Co. Inc.) regularly exhibited three distinct layers of calcium deposition in the mucosa, submucosa and muscularis of the stomach (Selye, r929).

These observations have assumed renewed interest for us more recently, when we found that certain types of pathological calcification depended largely upon the 'conditioning action' of adrenocortical hormones. Rats receiving a solution of $1 \%$ (w/v) $\mathrm{NaH}_{2} \mathrm{PO}_{4} \cdot \mathrm{H}_{2} \mathrm{O}$ or anhydrous $\mathrm{Na}_{2} \mathrm{HPO}_{4}$ in water as a drinking fluid tended to develop widespread calcification in the zona intermedia of the kidney if they were 